\title{
Solunum Yetmezlikli Yoğun Bakım Hastalarında Fosfat Düzeyleri
}

\author{
The Phosphate Levels of Critically ill Patients with Respiratory Failure
}

\author{
Mehmet Turan Inal, Dilek Memiş, Necdet Süt* \\ Trakya Üniversitesi Tıp Fakültesi Anesteziyoloji ve Reanimasyon Anabilim Dalı, Edirne, Türkiye \\ *Trakya Üniversitesi Tıp Fakültesi Biyoistatistik Anabilim Dalı, Edirne, Türkiye
}

\section{ÖZET}

Amaç: Hipofosfatemi yoğun bakım hastalarında sıklıkla görülmekte, mekanik ventilatörde ve yoğun bakımda kalış süresinde uzamaya neden olmaktadır. Bu çalışmamızda yoğun bakımda yatan hastalarda fosfat düzeylerinin prognostik değerini saptamayı amaçladık.

Gereç ve Yöntem: 1 Ocak 2009- 31 Aralık 2009 tarihleri arasında Trakya Üniversitesi Tıp Fakültesi yoğun bakımlarda solunum yetmezliği nedeniyle yatan tüm hastaların fosfat düzeyleri, yaş, cinsiyet, yatış süresi, mekanik ventilatörde kalış süresi, APACHE II skorları, kullandığı ilaçlar ve prognoz değerleri retrospektif olarak tarandı. Serum fosfat seviyesinin 2,5 mg/dL altında olması düşük ve 2,5-4,7 $\mathrm{mg} / \mathrm{dL}$ arasında olması normal düzey olarak kabul edildi.

Bulgular: Çalışmaya 139 hasta dahil edildi. Hastalardan \%41'inda düşük fosfat düzeyi saptandı. Gruplar arasında yaş, cinsiyet ve APACHE II skorları bakımından istatistiksel anlamlı farklılk saptanmadı. Fosfat düzeyinin düşük olduğu hastalarda yatış süresi $20,16 \pm 16,31$ gün olarak saptanırken, bu oran normal fosfat düzeyi saptanan hastalarda $12,62 \pm 12,43$ gün olarak bulundu $(p<0,05)$. Fosfat düzeyinin düşük olduğu grupta mekanik ventilatörde kalma süresi 17,54 $\pm 16,27$ gün olarak saptanırken, normal fosfat değerleri olan grupta bu oran $9,94 \pm 11,55$ gün olarak saptandı $(p<0,05)$. Düşük fosfat grubundaki hastalarda katekolamin, $\beta$-adrenerjik reseptör agonisti, diüretik ve glukokortikoid kullanımını daha fazla olduğu saptandı $(p<0,05)$.

Sonuç: Fosfat eksikliği neticesinde solunum yetmezlikli hastalarda mekanik ventilatör ve yoğun bakımda kalış süresi uzamaktadır. Fosfat eksikliğinin erken tanınması ve erken tedavisi için fosfat düzeylerinin sık şekilde takibini önermekteyiz. (Türk Yoğun Bakım Derneği Dergisi 2011; 9: 19-22)

Anahtar Kelimeler: Fosfat, yoğun bakım

\section{SUMMARY}

Objective: The incidence of hypophosphatemia is higher in critically ill patients and prolonged the length of ICU stay and duration of mechanical ventilation. This study evaluated the prognostic value of phosphate levels in critically ill patients.

Materials and Methods: All patients admitted to the general and surgical intensive care unit (ICU) of Trakya University Medical Faculty, with respiratory failure during 1 year period (from January 1, 2009, to December 31, 2009), were retrospectively enrolled. The phosphate levels, age, gender, length of ICU stay, duration of mechanical ventilation, APACHE II scores, medical drug usage and prognosis were recorded. Hypophosphataemia was defined as a level under $2.5 \mathrm{mg} / \mathrm{dL}$ and normophosphatemia was defined as a level between $2.5-4.7 \mathrm{mg} / \mathrm{dL}$.

Results: 139 patients were retrospectively enrolled into the study, of these, $41 \%$ had hypophosphataemia. There was no statistically significant difference in age, gender and APACHE II scores. The length of ICU stay was 20.16 \pm 16.31 days in hypophosphatemic patients and $12.62 \pm 12.43$ days in normophosphatemic patients $(p<0.05)$. The duration of mechanical ventilation was $17.54 \pm 16.27$ days in hypophosphatemic patients and $9.94 \pm 11.55$ days in normophosphatemic patients $(p<0.05)$. The usage of catecholamines, beta adrenergic receptor agonists, diuretics and glucocorticoids were higher in hypophosphatemic patients $(p<0.05)$.

Conclusion: The duration of mechanical ventilation and the length of ICU stay was prolonged in hypophosphatemic patients with respiratory failure. We suggested to follow the phosphate levels tightly for early diagnosis and treatment of phosphate deficiency. (Journal of the Turkish Society of Intensive Care 2011; 9: 19-22)

Key words: Phosphate, intensive care

Yazışma Adresi/Address for Correspondence: Dr. Mehmet Turan Inal, Trakya Üniversitesi Tıp Fakültesi, Anesteziyoloji ve Reanimasyon Anabilim Dall, 22030, Edirne, Türkiye Tel.: +90 2842357642 Faks: +90 2842358096 E-posta: mehmetturaninal@yahoo.com Geliş Tarihi/Received: 22.09.2010 Kabul Tarihi/Accepted: 04.02.2011 


\section{Giriş}

Hipofosfatemi elektrolit bozukluklarından birisidir. Genel popülasyonda sıklığı yüksek olmasa da hipofosfatemi sıklığı özel hasta gruplarında değişkenlik göstermektedir. Hastaneye yatan hastalarda hipofosfatemi oranı \%2,2-3,1 olarak bildirilirken, bu oran yoğun bakım hastalarında \%880 arasında değişmektedir. Sepsisli hastalarda \%65-80, majör travma hastalarında \% 75 ve kronik obstrüktif akciğer hastalığı olanlarda \%20 olarak bildirilmektedir (1-4).

Fosfat vücutta hücresel metabolizmada önemli etkileri olan bir elektrolittir. Vücudun en önemli enerji kaynağı olan adenozin trifosfat (ATP) sentezinde rol oynamaktadır. 2,3 difosfogliserat sentezi, hücre membranındaki fosfolipid yapımı, kemik mineralizasyonu ve değişik enzim sistemlerinin kofaktörü olarak da çalışmaktadır (5).

Serum fosfatının vücutta belirli seviyede kalması diyetle alım, gastrointestinal emilim, üriner atılım ve intraselüler ve ekstraselüler boşluklar arasındaki değişimlere bağlıdır. Fosfat intraselüler bölümün en önemli elektrolitlerinden biridir (5).

Hipofosfatemi sonucunda vücutta pek çok organ sistemi etkilenmektedir. Kas zayıflığı, miyalji ve anoreksi fosfat seviyesinin düşmesi neticesinde ilk olarak saptanan bulgulardır. Fosfat seviyeleri düştükçe parestezi, tremor, konfüzyon, nöbet geçirme ve koma görülebilmektedir (6). Rabdomiyolizis, hiperglisemi, hemoliz, trombosit fonksiyonlarında azalma, ventriküler taşikardi, doku oksijenlenmesinde azalma, kas zayıflıklarına bağlı solunum yetmezliği, hipotansiyon ve kalp yetmezliği fosfat yetersizliğinin ileri safhalarında sıklıkla görülmektedir (4-9).

Hipofosfateminin morbiditeyi ve mortaliteyi arttırdığı ve önemli bir prognostik faktör olduğu değişik çalışmalarla gösterilmiştir $(5,10,11)$.

Biz de çalışmamızda yoğun bakımda akut akciğer hasarı/akut solunum yetmezliği sendromu (ARDS) ve pnömoni nedeniyle yatan solunum yetmezlikli hastalarda fosfat düzeylerini ve fosfat düzeylerinin prognostik değerini saptamayı amaçladık.

\section{Gereç ve Yöntem}

1 Ocak 2009 - 31 Aralık 2009 tarihleri arasında cerrahi ve reanimasyon yoğun bakıma alınan akut akciğer hasarı/ARDS ve pnömoni tanısı konulmuş olup solunum yetmezliği nedeniyle yoğun bakımda izlenmesi gereken tüm hastaların fosfat değerleri retrospektif olarak tarandı. Akut başlayan, akciğer grafisinde yaygın bilatreral infiltrasyonlar gösteren, $\mathrm{PaO}_{2} / \mathrm{FiO}_{2} \leq 300 \mathrm{mmHg}$ ve PCWP $<18 \mathrm{mmHg}$ olan vakalar akut akciğer hasarı, akut başlayan, akciğer grafisinde yaygın bilateral infiltrasyonlar gösteren, $\mathrm{PaO}_{2} / \mathrm{FiO}_{2} \leq 200 \mathrm{mmHg}$ ve $\mathrm{PCWP}<18 \mathrm{mmHg}$ olan vakalar ise ARDS olarak kabul edildi (12). Pnömoni tanısı ise daha önceden bildirilmiş tanı kriterleri kullanılarak konuldu $(13,14)$.
Yoğun bakım protokolümüz gereği fosfat düzeylerine 3 gün arayla bakılmakta ve düşük değerler replase edilmekteydi. Tüm hastaların ilk fosfat değerleri kaydedildi. Ayrıca hastaların yaş, cinsiyet, yatış gün sayısı, mekanik ventilatörde kalış süresi, akut fizyoloji ve kronik sağlık değerlendirmesi skoru (APACHE II), kullandığı ilaçlar ve prognozları kaydedildi. Serum fosfat seviyesinin 2,5 mg/dL altında olması düşük ve 2,5-4,7 mg/dL arasında olması normal düzey olarak kabul edildi.

\section{İstatistiksel Analiz}

Veriler ortalama \pm standart. sapma ya da sayı olarak ifade edildi. Verilerin normal dağılıma uygunluğu tek örneklem Kolmogorov Smirnov test ile incelendi. Normal ve düşük fosfat gruplar arasında normal dağılım gösteren değişkenlerin karşılaştırılmasında student t testi, normal dağılım göstermeyenlerin karşılaştırılmasında Mann Whitney U testi kullanıldı. Kategorik verilerin karşılaştırımasında ki-kare testi kullanıldı. $P<0,05$ değeri istatistiksel anlamlılık sınırı olarak kabul edildi.

\section{Bulgular}

Çalışma süresi boyunca her iki yoğun bakıma yatırılan hasta sayısı 850 olarak saptandı. Bu hastalardan 139 tanesinde akut akciğer hasarı/ARDS ve pnömoni gelişmişti ve çalışmaya dahil edildi. Bu hastalardan 57'sinde (\%41) düşük fosfat düzeyi ve 82 'sinde (\%59) ise normal fosfat düzeyi saptandı. Gruplar arasında yaş, cinsiyet ve APACHE II skorları arasında istatistiksel anlamlı farklılık saptanmadı (Tablo 1).

Fosfat düzeyinin düşük olduğu 57 hastada mortalite oranı \% 14,03 olarak saptanırken, bu oran normal fosfat düzeyi olan grupta \% 19,5 olarak saptandı. Gruplar arasında mortalite oranları arasında istatistiksel anlamlı farklılık saptanmadı ( $p>0,05)$ (Tablo 2).

Düşük fosfat düzeyi saptanan hastalarda yatış süresi $20,16 \pm 16,31$ gün olarak saptanırken, bu oran normal fosfat düzeyi saptanan hastalarda 12,62 $\pm 12,43$ gün olarak bulundu. Gruplar arasında istatistiksel anlamlı farklılık saptandı $(p<0,05)$ (Tablo 2$)$.

Fosfat düzeyinin düşük olduğu grupta mekanik ventilatörde kalma süresi 17,54+16,27 gün olarak saptanır-

\begin{tabular}{|c|c|c|}
\hline & $\begin{array}{c}\text { Düşük fosfat grubu } \\
\begin{array}{c}(p<2,5 \mathrm{mg} / \mathrm{dL}) \\
n=57\end{array}\end{array}$ & $\begin{array}{c}\text { Normal fosfat grubu } \\
\begin{array}{c}(p=2,5-4,7 \mathrm{mg} / \mathrm{dL}) \\
n=82\end{array}\end{array}$ \\
\hline 'aş (yıl) & $61,68 \pm 18,36$ & $58,63 \pm 19,30$ \\
\hline insiyet (K/E) & $28 / 29$ & $38 / 44$ \\
\hline PACHE II skorları & $20,16 \pm 8,24$ & $19,44 \pm 7,87$ \\
\hline anı Pnömoni & 10 & 12 \\
\hline 7) $\mathrm{ARDS}$ & 47 & 70 \\
\hline
\end{tabular}

Değerler ort \pm std sapma olarak verilmiştir APACHE skoru: Akut fizyoloji ve kronik sağlık değerlendirmesi skoru 
ken, normal fosfat değerleri olan grupta bu oran $9,94 \pm 11,55$ gün olarak saptandı. Gruplar arasında istatistiksel anlamlı farklılık bulundu $(p<0,05)$ (Tablo 2$)$.

Düşük fosfat grubundaki hastalarda katekolamin, ,-adrenerjik reseptör agonisti, diüretik ve glukokortikoid kullanımının daha fazla olduğu saptandı $(p<0,05)$ (Tablo 3).

\section{Tartışma}

Yoğun bakım hastalarında düşük fosfat düzeyi mekanik ventilatörde ve yoğun bakımda kalış süresini arttıran önemli sağlık sorunlarından birisidir. Yoğun bakım hastalarında fosfat düzeylerinin takip edilmesi ve replase edilmesi zorunludur. Biz de bu retrospektif çalışmada yoğun bakımlarda solunum yetmezliği ile takip edilen hastalarda fosfat düzeyleri ve prognoz ilişkisini araştırmaya çalıştık.

Yoğun bakımlarda ve hastanede yatan hastalarda fosfat düzeyleri ile ilgili değişik çalışmalar bulunmaktadır $(2,5,11,15)$. Gaasbeek ve ark (2) çalışmalarında yoğun bakımlarda fosfat eksikliği insidansını \%28-34 arasında bildirirken, Hoffman ve ark (5) çalışmalarında bu oranı \% 45 civarında bulmuştur. Giovannini ve ark. (11) ise hipofosfatemi oranını \%64 olarak bildirmişlerdir. Zazzo ve ark (15) çalışmalarında yoğun bakım hastalarında fosfat düşüklüğü insidansını \%44,8 olarak saptanmıştır. Solunum yetmezliği olan hastalarda hipofosfateminin sıklıkla görüldüğü yapılan çalışmalarda bildirilmektedir (16-18). Alamoudi ve ark.'nın (16) yaptıkları çalışmada kronik stabil astımı olan hastalarda fosfat düzeylerine bakılmış ve hipofosfatemi oranı \%15 olarak bildirilmiştir. Bu duruma neden öne sürülememiştir. Biz de çalışmamızda solunum yetmezliği gelişen hastaların \%41'inde serum fosfat düzeyini düšük olarak saptadık.

Yoğun bakımlarda pek çok nedenden dolayı hipofosfatemiye rastlanmaktadır. Fosfattan fakir beslenme uygulamaları ve yoğun bakımlarda kullanılan ilaçlar (katekolaminler, $\beta$-adrenerjik reseptör agonistleri, diüretikler, mannitol, glukokortikoidler) sıklıkla hipofosfatemi oluşturmaktadır. Ayrıca travma, yanık ve malnütrisyon gibi durumlarda da sıklıkla hipofosfatemi görülmektedir (19). Başka bir çalışmada da (17) kronik obstrüktif pulmoner hastalığı

\begin{tabular}{|c|c|c|}
\hline & $\begin{array}{c}\text { Düşük fosfat grubu } \\
\qquad \begin{array}{c}(p<2,5 \mathrm{mg} / \mathrm{dL}) \\
n=57\end{array}\end{array}$ & $\begin{array}{l}\text { Normal fosfat grubu } \\
\begin{array}{c}(p=2,5-4,7 \mathrm{mg} / \mathrm{dL}) \\
n=82\end{array}\end{array}$ \\
\hline Mortalite (n) & $8(\% 14,03)$ & $16(\% 19,5)$ \\
\hline Yatış süresi (gün) & * $20,16 \pm 16,31$ & $12,62 \pm 12,43$ \\
\hline $\begin{array}{l}\text { Mekanik ventilatörde } \\
\text { kalma süresi (gün) }\end{array}$ & 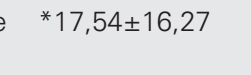 & $9,94 \pm 11,55$ \\
\hline \multicolumn{3}{|c|}{$\begin{array}{l}\text { Değerler ort } \pm \text { std sapma olarak verilmiştir } \\
{ }^{*} p<0,05\end{array}$} \\
\hline
\end{tabular}

olan bireylerde hipofosfatemi oran \%21 olarak bulunmuş ve bu duruma hastaların kronik olarak kullandığı kortikosteroid, loop diüretikleri ve,-adrenerjik bronkodilatatörlerin yol açtığı saptanmıştır. Fisher (18) ise çalışmasında hipofosfatemi oranını \%17 olarak saptanmıştır. Bu durum solunum yetmezliği olan hastaların kullandıkları medikal ilaçlara bağlanmıştır. Biz çalışmamızda solunum yetmezliği olan hastalarda hipofosfatemi oranını \%41 olarak saptadık. Bu durumu hipofosfatemik hastalarda daha sık kortikosteroid, loop diüretikleri ve $\beta$-adrenerjik bronkodilatatörlerin kullanılması ile ilişkili olduğunu düşünmekteyiz

Hipofosfatemi neticesinde mekanik ventilatörden ayırmada gecikme ve yoğun bakımda kalış süresinde uzama, miyokardiyal disfonksiyon, santral ve periferik sinir sisteminde etkilenmeler ve kas gücünde azalma olduğu bilinmektedir (19).

Fisher (18) çalışmasında hipofosfatemik hastalarda hastanede yatış günü sayısının normal düzeyleri olan hastalara göre iki kat fazla olduğu rapor edilmiştir. Marik de çalışmasında (20) hipofosfatemi saptanan hastalarda hastanede kalış süresinde uzama olduğunu bildirmiştir. Bu çalışmamızda düşük fosfat düzeyi saptanan hastalarda normal fosfat düzeyleri olan hastalara göre yatış süresinde uzama saptadık. Her iki grup arasında istatistiksel anlamlı farklılık bulundu.

Fosfat düşüklüğü olan hastalarda mekanik ventilatörde kalış süresinde ve mekanik ventilatörden ayırma süresinde uzama olduğu yapılan çalışmalarda bildirilmektedir $(21,22)$. Agusti ve ark $(21)$ yaptıkları çalışmada hastanın mekanik ventilatörden sağlıklı şekilde ayrılmasında normal fosfat değerlerinin önemine dikkat çekmişlerdir. Aubier ve ark (22) ise yaptıkları çalışmada fosfatın solunum fonksiyonları üzerine etkisini değerlendirmişler ve solunum kaslarının kasılması için normal fosfat düzeylerine ihtiyaç olduğunu bildirmişlerdir. Biz de çalışmamızda fosfat düzeyi düşük hastalarda mekanik ventilatör desteğinin normal fosfat düzeyi olan hastalardan daha uzun olduğunu saptadık. Bu durumun düşük fosfat düzeylerinin solunum kaslarına olan negatif etkisi sonucu geliştiğini düşünmekteyiz.

Fosfat düşüklüğünün hastalarda mortaliteye etkisi değişik çalışmalarda araştırımıştır. Giovannini (11) çalışma-

Tablo 3. Kullanilan medikal tedaviler

\begin{tabular}{lcc}
\hline & $\begin{array}{c}\text { Düşük fosfat grubu } \\
(p<2,5 \mathrm{mg} / \mathrm{dL}) \\
n=57\end{array}$ & $\begin{array}{c}\text { Normal fosfat grubu } \\
(\mathrm{p}=2,5-4,7 \mathrm{mg} / \mathrm{dL}) \\
n=82\end{array}$ \\
\hline Katekolaminler & ${ }^{*} 43$ & 45 \\
$\beta$-adrenerjik reseptör & $* 45$ & 30 \\
agonistleri & & \\
Diüretikler & $* 39$ & 40 \\
Glukokortikoidler & $* 13$ & 7 \\
\hline${ }^{*} p<0,05$ & & \\
\hline
\end{tabular}


sında hipofosfatemik hastalarda mortalite oranını \%22 olarak saptanmıştır. Biz de çalışmamızda hipofosfatemik hastalarda mortalite oranını \%14,03 olarak saptadık. Fosfat düzeyi normal hastalarda ise mortalite oranını \%19,5 olarak bulduk. Her iki grup hastalarda istatistiksel anlamlı farklılık bulunmadı.

Fosfat eksikliği solunum yetmezlikli hastalarda morbidite ve mortalitede artış oluşturmaktadır ve önemli bir prognostik faktördür. Fosfat eksikliğinin erken tanınması ve erken tedavi edilmesi mekanik ventilatör ve yoğun bakımda kalış süresinde azalmalara yol açacaktır. Sonuç olarak yoğun bakım hastalarında fosfat düzeylerinin sık şekilde takibini önermekteyiz.

\section{Kaynaklar}

1. Brunelli SM, Goldfarb S. Hypophosphatemia: clinical consequences and management. J Am Soc Nephrol 2007;18:19992003.

2. Gaasbeek A, Meinders AE. Hypophosphatemia: an update on its etiology and treatment. Am J Med 2005:118:1094-101.

3. Charron T, Bernard F, Skrobik Y, Simoneau N, Gagnon N, Leblanc M. Intravenous phosphate in the intensive care unit: more aggressive repletion regimens for moderate and severe hypophosphatemia. Intensive Care Med 2003;29:1273-8.

4. Brown GR, Greenwood JK. Drug- and nutrition-induced hypophosphatemia: mechanisms and relevance in the critically ill. Ann Pharmacother 1994;28:626-32.

5. Hoffmann $M$, Zemlin AE, Meyer WP, Erasmus RT. Hypophosphataemia at a large academic hospital in South Africa. J Clin Pathol 2008;61:1104-7.

6. Weisinger JR, Bellor'n-Font E. Magnesium and phosphorus. Lancet 1998:352:391-6.

7. Knochel JP. Hypophosphatemia and rhabdomyolysis. Am J Med 1992;92:455-7.

8. Fiaccadori E, Coffrini E, Ronda N, Vezzani A, Cacciani G, Fracchia $\mathrm{C}$, et al. Hypophosphatemia in course of chronic obstructive pulmonary disease. Prevalence, mechanisms, and relationships with skeletal muscle phosphorus content. Chest 1990;97:857-68.

9. Alamoudi OS. Electrolyte disturbances in patients with chronic, stable asthma: effect of therapy. Chest 2001; 120:431-6.
10. Shor R, Halabe A, Rishver S, Tilis Y, Matas Z, Fux A, et al. Severe hypophosphatemia in sepsis as a mortality predictor. Ann Clin Lab Sci 2006;36:67-72.

11. Giovannini I, Chiarla C, Nuzzo G. Pathophysiologic and clinical correlates of hypophosphatemia and the relationship with sepsis and outcome in postoperative patients after hepatectomy. Shock 2002:18:111-5.

12. Bernard GR, Artigas A, Brigham KL, Carlet J, Falke K, Hudson L, et al. Report of the American-European Consensus conference on acute respiratory distress syndrome: definitions, mechanisms, relevant outcomes, and clinical trial coordination. Consensus Committee. J Crit Care 199:9:72-81.

13. Mandell LA, Wunderink RG, Anzueto A, Bartlett JG, Campbell GD, Dean NC, et al. Infectious Diseases Society of America/American Thoracic Society consensus guidelines on the management of community-acquired pneumonia in adults. Clin Infect Dis 2007:44:27-72.

14. Soo Hoo GW, Wen YE, Nguyen TV, Goetz MB. Impact of clinical guidelines in the management of severe hospital-acquired pneumonia. Chest 2005:128:2778-87.

15. Zazzo JF, Troché G, Ruel P, Maintenant J. High incidence of hypophosphatemia in surgical intensive care patients: efficacy of phosphorus therapy on myocardial function. Intensive Care Med 1995;21:826-31.

16. Alamoudi OS. Electrolyte disturbances in patients with chronic, stable asthma: effect of therapy. Chest 2001;120:431-6.

17. Fiaccadori E, Coffrini E, Ronda N, Vezzani A, Cacciani G, Fracchia $\mathrm{C}$, et al. Hypophosphatemia in course of chronic obstructive pulmonary disease. Prevalence, mechanisms, and relationships with skeletal muscle phosphorus content. Chest 1990:97:857-68.

18. Fisher J, Magid N, Kallman C, Fanucchi M, Klein L, McCarthy D, et al. Respiratory illness and hypophosphatemia. Chest 1983:83:504-8.

19. Bugg NC, Jones JA. Hypophosphataemia. Pathophysiology, effects and management on the intensive care unit. Anaesthesia 1998;53:895-902.

20. Marik PE, Bedigian MK. Refeeding hypophosphatemia in critically ill patients in an intensive care unit. A prospective study. Arch Surg 1996;131:1043-7.

21. Agusti AG, Torres A, Estopa R, Agustividal A. Hypophosphatemia as a cause of failed weaning: the importance of metabolic factors. Crit Care Med 1984;12:142-3.

22. Aubier M, Murciano D, Lecocquic $Y$, Viires $N$, Jacquens $Y$, Squara $P$, et al. Effect of hypophosphatemia on diaphragmatic contractility in patients with acute respiratory failure. $\mathrm{N}$ Engl $\mathrm{J}$ Med $1985: 313: 420-4$ 